\title{
Electrochromic Properties of Polyaniline-Based Hybrid Organic/Inorganic Materials
}

\author{
Rosanny C. Silva, ${ }^{a}$ Marina V. Sarmento, ${ }^{a}$ Roselena Faez, ${ }^{b}$ Roger J. Mortimer ${ }^{\dagger, c}$ and \\ Adriana S. Ribeiro*,a
}

anstituto de Química e Biotecnologia, Universidade Federal de Alagoas, Campus A. C. Simões, 57072-970 Maceió-AL, Brazil

${ }^{b}$ Laboratório de Materiais Poliméricos e Biossorventes, Universidade Federal de São Carlos, Campus Araras, 13604-900 Araras-SP, Brazil

${ }^{c}$ Department of Chemistry, Loughborough University, LE11 $3 T U$ Loughborough-LT, United Kingdom

\begin{abstract}
Hybrid materials based on polyaniline (PAni) were obtained by in situ polymerization of aniline with chitosan and/or organically modified clay (nanomer I-24) in $\mathrm{HCl}$. The samples were characterized by Fourier transform infrared (FTIR) spectroscopy, X-ray diffraction (XRD), scanning electron microscopy (SEM) and direct current (DC) electrical conductivity. Thin films of PAni, PAni-clay, PAni-chitosan and PAni-chitosan-clay were prepared by casting a solution of each sample in $N$-methyl-2-pyrrolidone (NMP) onto indium tin oxide (ITO)/glass electrodes and their electrochromic properties were investigated. It was observed color variation from transparent yellow in the reduced state $(\mathrm{E}=-0.2 \mathrm{~V} v s . \mathrm{Ag} / \mathrm{AgCl})$, green in the intermediate state $(\mathrm{E}=0.5 \mathrm{~V})$ and dark blue in the oxidized state $(\mathrm{E}=0.8 \mathrm{~V})$ for all samples. The color changes of each material in function of the applied potential were tracked using the Commission Internationale de l'Eclairage (CIE) system of colorimetry, in which the color change was much more significant for PAni-clay film.
\end{abstract}

Keywords: conjugated polymer, hybrid material, polyaniline, chitosan, organophilic clay

\section{Introduction}

Conjugated polymers have attracted the attention of academia and industries mainly because of their electrical, magnetic, and optical properties, which make them useful for applications in organic optoelectronic devices. Currently, the development of new hybrid materials based on conjugated polymers have afforded materials with excellent characteristics for application in organic light emitting diodes (OLEDs) ${ }^{1,2}$ organic field effect transistors (OFETs), ${ }^{3}$ organic solar cells (OSCs), ${ }^{4}$ and electrochromic devices (ECDs)..$^{5-7}$

Electrochromic materials based on conjugated polymers show many interesting properties such as multicolor, fast switching speed, flexibility and easy to optimize their properties through molecular tailoring. ${ }^{8,9}$ Among the organic polymeric electrochromic materials, polyaniline (PAni) has

*e-mail: aribeiro@qui.ufal.br

${ }^{\dagger}$ In memoriam been widely studied due to many advantageous properties including high optical contrast $(\Delta \% \mathrm{~T})$, environmental stability, easy synthesis, as well as comparatively low cost. ${ }^{8}$ Furthermore, the high pseudocapacitance arising from the versatile redox reactions and its corresponding color changes make PAni promising candidate for electrochemical capacitors ${ }^{10,11}$ and ECDs..$^{12,13}$ However, the difficulties in processing of PAni into films due to its very low solubility in most of the available solvents and the relatively poor mechanical properties decrease its performances and utilities in such applications.

Despite PAni can be synthesized by chemical ${ }^{14}$ or electrochemical ${ }^{15}$ polymerization methods described in the literature, PAni films with good mechanical properties and adherence to a surface are not usually achieved from the conventional chemical methods of synthesis, which yield PAni as an insoluble and infusible bulky powder. ${ }^{16}$ In order to increase the processability and mechanical properties of PAni, significant efforts have been done in preparation of blends based on PAni with other appropriate polymers that 
have good physical properties, ${ }^{17,18}$ such as polystyrene, ${ }^{19}$ polyamide, ${ }^{20}$ and polysaccharides like cellulose, starch and chitosan. ${ }^{21-23}$

Recently, in addition of the mixture of PAni with other polymers, it has been sought to improve such properties through the preparation of hybrid organic/inorganic composites by the incorporation of metal oxides (such as $\mathrm{WO}_{3}, \mathrm{NiFe}_{2} \mathrm{O}_{4}, \mathrm{TiO}_{2}$ and $\left.\mathrm{ZnO}\right),{ }^{8,24-27}$ montmorillonite clays ${ }^{28}$ or mesoporous materials such as SBA-15 and MCM-41, ${ }^{29,30}$ since they combine the advantages of conjugated conducting polymers and these fillers offering special properties arising from the combination of each component. Undertaking this challenge provides an opportunity for developing new materials with synergic behavior leading to improved performance or to new useful properties.

Our group has been synthesizing and characterizing a series of conjugated polymers, mainly polypyrrole, polythiophene and PAni derivatives and composites, aiming at their application in electrochromic devices. ${ }^{7,31-37}$ In the present paper, PAni, chitosan and clay hybrid materials were prepared in hydrochloric acid $(\mathrm{HCl})$ medium in order to investigate the electrochromic properties of these materials in aqueous acid medium and to quantify the color changes of each hybrid material using the Commission Internationale de l'Eclairage (CIE) principles, ${ }^{38,39}$ aiming their application as active layers in ECDs.

\section{Experimental}

\section{Chemicals}

Aniline was distilled before use. Chitosan (deacetylation degree 85\%; molecular weight 100,000-300,000), ammonium persulfate $\left[\left(\mathrm{NH}_{4}\right)_{2} \mathrm{~S}_{2} \mathrm{O}_{8}\right], \mathrm{N}$-methyl-2pyrrolidone (NMP), lithium perchlorate $\left(\mathrm{LiClO}_{4}\right), \mathrm{HCl}$ and perchloric acid $\left(\mathrm{HClO}_{4}\right)$ were used as received. Organically modified montmorillonite clay (nanomer I-24) was supplied by Nanocor Inc., AMCOL International Corporation.

\section{PAni synthesis}

One milliliter of freshly distilled aniline was dissolved in $10.0 \mathrm{~mL}$ of $1.0 \mathrm{~mol} \mathrm{~L}^{-1} \mathrm{HCl}$ and the solution was cooled to $-10{ }^{\circ} \mathrm{C}$. A solution containing $3.0 \mathrm{~g}$ of $\left(\mathrm{NH}_{4}\right)_{2} \mathrm{~S}_{2} \mathrm{O}_{8}$ dissolved in $40 \mathrm{~mL}$ of $1.0 \mathrm{~mol} \mathrm{~L}^{-1} \mathrm{HCl}$ was slowly poured into the monomer solution, under vigorous stirring. The reaction temperature was maintained at $-10^{\circ} \mathrm{C}$ for $2 \mathrm{~h}$. After this period, a dark green precipitate was recovered from the reaction mixture by filtration under reduced pressure and washed thoroughly with $50 \mathrm{~mL}$ of $1.0 \mathrm{~mol} \mathrm{~L}^{-1} \mathrm{HCl}$. The final powder product was dried under vacuum.

\section{In situ synthesis of hybrid materials}

PAni-clay samples were obtained by stirring $25 \mathrm{mg}$ of nanomer I-24 and $50 \mathrm{~mL}$ of $1.0 \mathrm{~mol} \mathrm{~L}^{-1} \mathrm{HCl}$ for $24 \mathrm{~h}$ in order to swell the clay. Then, $1.0 \mathrm{~mL}$ of aniline was added to the clay/ $\mathrm{HCl}$ mixture and stirred for $1 \mathrm{~h}$.

PAni-chitosan samples were obtained by adding $0.5 \mathrm{~g}$ of chitosan to $50 \mathrm{~mL}$ of $0.1 \mathrm{~mol} \mathrm{~L}^{-1} \mathrm{HCl}$ and the resulting solution was stirred for $2 \mathrm{~h}$. Next, $1.0 \mathrm{~mL}$ of aniline was added to the solution and the mixture was stirred for $1 \mathrm{~h}$.

PAni-chitosan-clay samples were prepared by mixing $25 \mathrm{mg}$ of nanomer I-24 and $50 \mathrm{~mL}$ of $1.0 \mathrm{~mol} \mathrm{~L}^{-1} \mathrm{HCl}$ for $24 \mathrm{~h}$, followed by addition of $0.5 \mathrm{~g}$ of chitosan and stirring for $2 \mathrm{~h}$. One milliliter of aniline was then added, and the solution was stirred for $1 \mathrm{~h}$.

In all the preparations, the polymerization step using $\left(\mathrm{NH}_{4}\right)_{2} \mathrm{~S}_{2} \mathrm{O}_{8}$ as oxidizing agent was accomplished as in the case of the PAni synthesis. The aniline, chitosan, and/or clay ratios used to prepare each sample are shown in Table 1.

Table 1. Proportions (in weight, wt.\%) of aniline, clay and/or chitosan used in the synthesis of the polyaniline (PAni) hybrid composites

\begin{tabular}{lccc}
\hline Sample & $\begin{array}{c}\text { Aniline / } \\
\text { wt.\% }\end{array}$ & $\begin{array}{c}\text { Clay / } \\
\text { wt.\% }\end{array}$ & $\begin{array}{c}\text { Chitosan / } \\
\text { wt.\% }\end{array}$ \\
\hline PAni & 100 & - & - \\
PAni-clay & 97.56 & 2.44 & - \\
PAni-chitosan & 66.67 & - & 33.33 \\
PAni-chitosan-clay & 65.57 & 1.64 & 32.78 \\
\hline
\end{tabular}

Deposition of the films onto indium tin oxide (ITO)/glass

Ten milligrams of each sample (PAni, PAni-clay, PAnichitosan and PAni-chitosan-clay) were dissolved in $1.0 \mathrm{~mL}$ of NMP. The films were obtained by casting $\left(100 \mu \mathrm{L} \mathrm{cm}^{-2}\right)$ onto ITO/glass electrodes (Delta Technologies, Loveland, CO, USA; Rs ca. $10 \Omega \mathrm{cm})$. The covered area of each electrode $\left(1.0 \mathrm{~cm}^{2}\right)$ was delimited by an adhesive tape and the coated electrodes were allowed to dry for $48 \mathrm{~h}$ at room temperature in a covered container. Each film was prepared using exactly the same conditions to guarantee that the films have similar thickness.

\section{Characterization of the samples}

Fourier transform infrared (FTIR) spectra were recorded using a Shimadzu IR-Prestige-21 spectrophotometer 
(Kyoto, Japan). X-Ray diffraction (XRD) patterns of powdered samples were recorded on a Rigaku diffractometer model MiniFlex (Tokyo, Japan) using $\mathrm{Cu}-\mathrm{K} \alpha$ radiation. Scanning electron microscopy (SEM) images were recorded on a JEOL field emission scanning electron microscope, model JSM-7401F (Tokyo, Japan) using a secondary electron image (SEI) detector.

The electrical conductivity was measured by a fourpoint method using a Jandel multi height probe with Jandel cylindrical probe head $(25.4 \mathrm{~nm}$ diameter $\times 48.5 \mathrm{~nm}$ high), tip spacing of $1.591 \mathrm{~nm}$ controlled by the RM3-AR test unit (Jandel Engineering Ltd., Linslade, UK). The pressed pellets (15 $\mathrm{mm}$ in diameter and $0.50 \mathrm{~mm}$ in thickness) used in this measurement were prepared using $120 \mathrm{mg}$ of the sample. Electrical conductivity of the pressed pellet was an average of eight values measured from two sides and in different places.

\section{Spectroelectrochemistry}

The characterization of the films deposited onto ITO/ glass electrodes was carried out using an Metrohm Autolab PGSTAT30 potentiostat interfaced with a computer, using the software provided by Autolab (Utrecht, Netherlands). A onecompartment, three-electrode cell was used to characterize the films. A platinum wire was used as counter electrode and $\mathrm{Ag} / \mathrm{AgCl}\left(\mathrm{KCl}_{\text {sat. }}\right)$ was employed as reference electrode.

The films were characterized by cyclic voltammetry in $0.1 \mathrm{~mol} \mathrm{~L}^{-1} \mathrm{LiClO}_{4} / \mathrm{HClO}_{4}\left(0.1 \mathrm{~mol} \mathrm{~L}^{-1}\right)$ electrolyte. Cyclic voltammograms were acquired within the fixed potential scan range of $-0.2 \leq \mathrm{E} \leq 0.8 \mathrm{~V} v s$. $\mathrm{Ag} / \mathrm{AgCl}$ at a scan rate of $0.02 \mathrm{~V} \mathrm{~s}^{-1}$. Spectra were concurrently recorded in the range $300-1100 \mathrm{~nm}$ by employing an optical glass cuvette placed in the sample compartment of a Hewlett-Packard 8453 spectrophotometer (Palo Alto, CA, USA).

Color measurements of CIE 1931 xy chromaticity coordinates were performed using a Microsoft Excel ${ }^{\circledR}$ (Redmond, WA, USA) spreadsheet developed by Mortimer and Varley. ${ }^{38,39}$ For simulation of midmorning to midafternoon natural light, the relative power distribution of a D55 constant temperature (5500 K blackbody radiation) standard illuminant was used in the calculations. Chromaticity coordinates were also transformed to $L * a * b *$ coordinates, a uniform color space (CIELAB) defined by the CIE in 1976.

\section{Results and Discussion}

FTIR analysis

FTIR spectra of chitosan, PAni, PAni-clay, PAni-chitosan and PAni-chitosan-clay samples were recorded in order to confirm the PAni formation and to investigate its interaction with chitosan in all the systems. For PAni-chitosan sample (Figure 1b), FTIR spectrum exhibits typical absorption bands characteristic of chitosan $(1656,1595,1427,1379$, 1155 and $1078 \mathrm{~cm}^{-1}$ ) 40,41 and PAni (peaks at around 1600, 1500, 1300 and $\left.790 \mathrm{~cm}^{-1}\right) .42,43$ The bands associated with PAni remain unaltered in the FTIR spectra of the PAni-chitosan-clay and PAni-clay samples (Figures 1c and $1 \mathrm{~d}$, respectively).

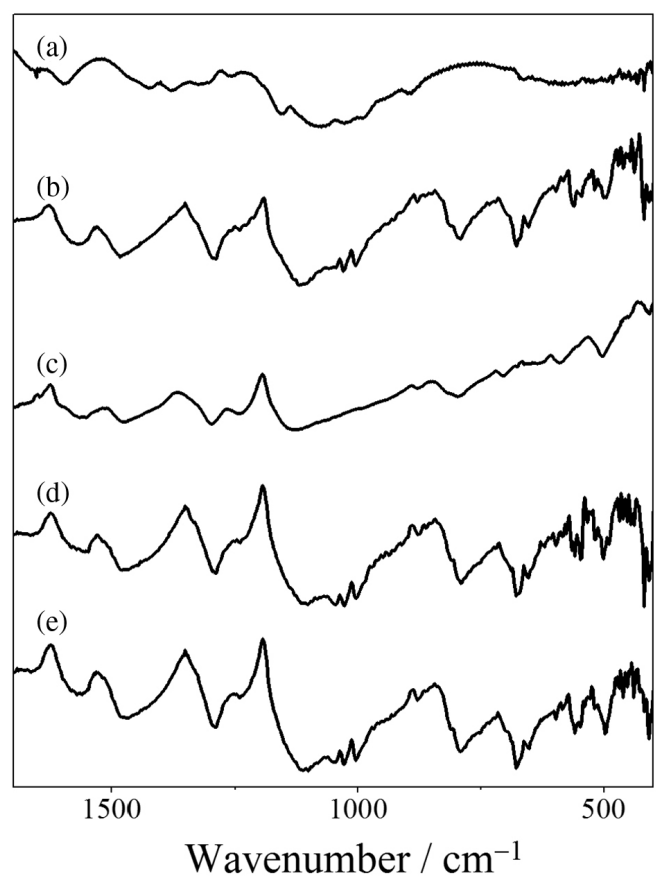

Figure 1. Fourier transform infrared (FTIR) spectra for (a) chitosan; (b) polyaniline (PAni)-chitosan; (c) PAni-chitosan-clay; (d) PAni-clay; and (e) PAni.

\section{XRD analysis}

On the basis of the strength of the PAni-clay interaction, structurally two different types of nanocomposites are thermodynamically achievable: $(i)$ intercalated structures, where insertion of PAni chains into the interlayer of the clay lamellae occurs in a crystallographically regular fashion and a repeat distance of few nanometers; and (ii) exfoliated structures, in which the individual silicate layers are separated in polymer matrix. ${ }^{44}$ The state of intercalation or exfoliation of nanoparticles has been established using XRD analysis by monitoring the position, shape, and intensity of the basal reflections from the distributed silicate layers.

The XRD patterns of the clay (Figure 2a), chitosan (Figure 2b) and PAni (Figure 2c) display the characteristics peaks regarding each material. The reflection at $2 \theta=6.7^{\circ}$ showed in Figure $2 \mathrm{a}$ is assigned to the $\mathrm{d}_{001}$ spacing of the 

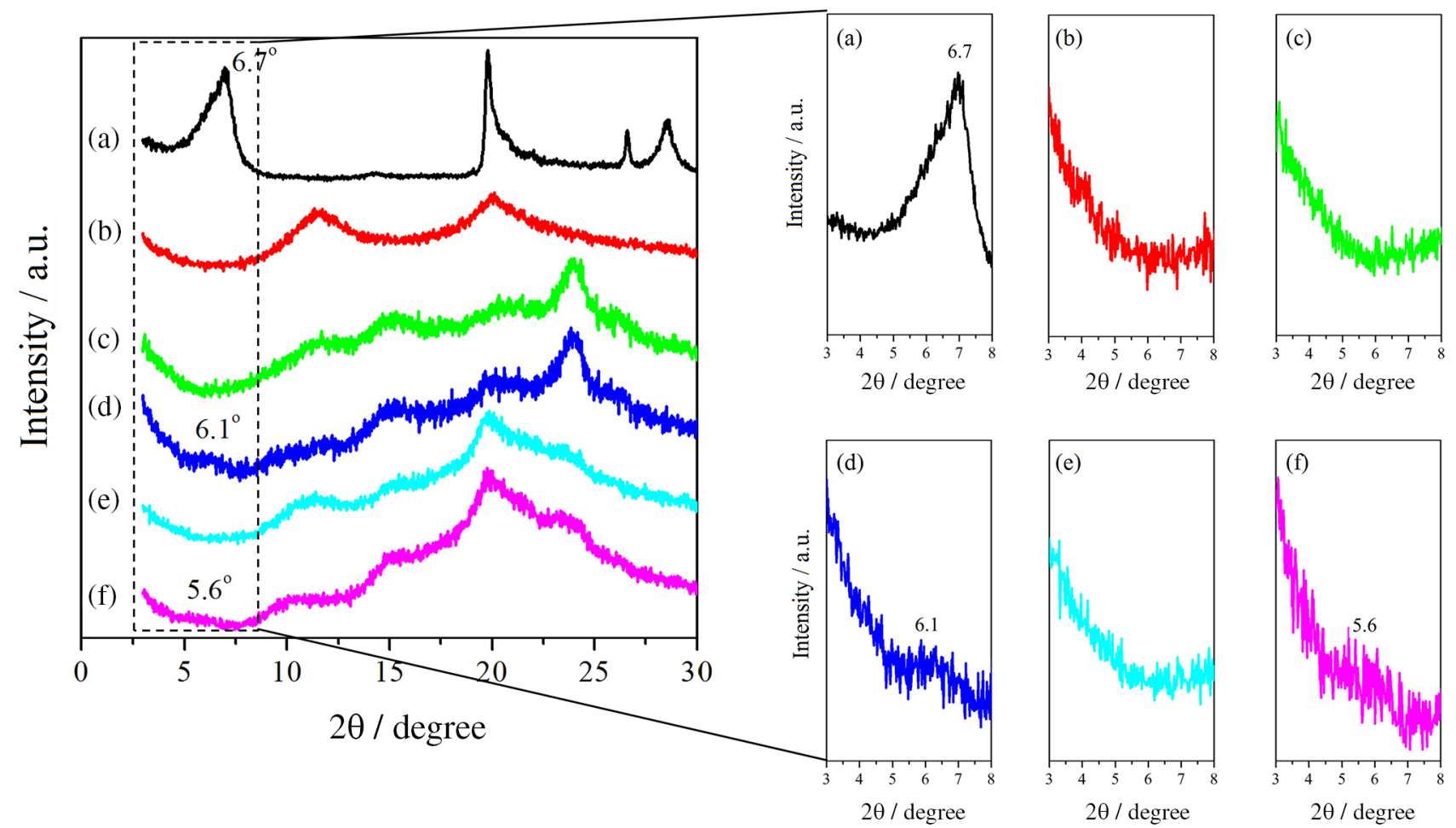

Figure 2. X-ray diffraction (XRD) patterns of (a) nanomer I-24 clay; (b) chitosan; (c) polyaniline (PAni); (d) PAni-clay; (e) PAni-chitosan; and (f) PAnichitosan-clay.

clay. In Figure $2 b$ it is possible to observe reflections at $2 \theta=11.5$ and $20.1^{\circ}$, which is consistent with previous studies reporting the reflection pattern of chitosan, ${ }^{43,45}$ and can be attributed to the existence of amorphous and crystalline regions, respectively. ${ }^{46,47}$ The XRD pattern of the PAni (Figure 2c) shows the main characteristic peaks of the PAni crystalline orthorhombic structure at $2 \theta=11.4$, $15.2,20.5$ and $24.0^{\circ}$, corresponding respectively to the basal planes (001), (010), (100) and (110). ${ }^{48}$

In order to evaluate the interactions between PAni, chitosan and clay, the variation of d-spacing was calculated for each sample according to the Bragg's law from the angular position $2 \theta$ of the observed peaks shown in Figure 2. The main reflections of the clay, chitosan and PAni were observed in the XRD patterns of each material. For the clay intercalated structures, the PAni chains get confined in the interlayers of the clay (nevertheless PAni chains should also be outside clay galleries) and the distance between the clay layers increases ${ }^{49}$ so that the intercalation of the PAni and PAni-chitosan into the clay interlayer (Figures $2 \mathrm{~d}$ and $2 \mathrm{f}$ ) was confirmed by the decrease of $2 \theta$ from $6.7^{\circ}$ (clay) to $6.1^{\circ}$ (PAni-clay) and $5.6^{\circ}$ (PAni-chitosan-clay). Taking into account the thickness of the silicate layer (about $1.32 \mathrm{~nm}$ ), the increase of the interlayer distance was calculated from the corresponding $\mathrm{d}_{001}$ spacing as being $1.45 \mathrm{~nm}$ for the PAni-clay and $1.58 \mathrm{~nm}$ for the PAni-chitosan-clay samples.
The XRD patterns of the PAni-chitosan (Figure 2e) and PAni-chitosan-clay (Figure 2f) show a decrease in the relative intensity of the peak at $2 \theta=24.0^{\circ}$ when compared to the other characteristic reflections of the PAni, which can be related to the decrease in the degree of crystallinity of the polymer, i.e., formation of more amorphous structures. ${ }^{23}$ The comparison of these results with that found in an earlier work for samples prepared in $p$-toluenesulfonic acid (PTSA $)^{37}$ suggests that the way of interaction between PAni and chitosan depends on the synthesis medium. The analysis of the XRD pattern of the PAni-chitosan prepared in PTSA, shown in reference 37, indicates the formation of a grafted copolymer of PAni and chitosan. On the other hand, the XRD patterns of the PAni-chitosan samples prepared in $\mathrm{HCl}$ does not show the same behavior. In this case, a decrease in the degree of crystallinity of the material occurs, since the presence of chitosan prevents the formation of defined crystalline phases, which suggests the formation of a composite between PAni and chitosan.

These differences in the behavior of PAni-chitosan and PAni-chitosan-clay films synthesized in $\mathrm{HCl}$ and PTSA may be explained by the size of the dopant agent. PTSA is a bulky organic acid that can improve linearity of the PAni chain making it more susceptible to interchain reactions, or even with other polymers, such as chitosan. However, as $\mathrm{HCl}$ is smaller than PTSA, it makes the polymer more coiled and then less prone to side reactions. 


\section{Morphology}

The SEM images of the PAni (Figure 3a), PAni-clay (Figure 3b), PAni-chitosan (Figure 3c) and PAni-chitosanclay (Figure 3d) show a characteristic rough morphology with globular grains and some agglomerates connected by fibrils, except for the PAni-clay sample that exhibits a more homogeneous and compacted aggregates with only a few evident fibrils.

According to Zhang et al.,$^{50}$ chemical oxidative polymerization of aniline in aqueous acid using $\left(\mathrm{NH}_{4}\right)_{2} \mathrm{~S}_{2} \mathrm{O}_{8}$ as oxidant agent proceeds through the formation of large aggregates that act as seeds, influencing the overall morphology of the polymer. These aggregates

(a)

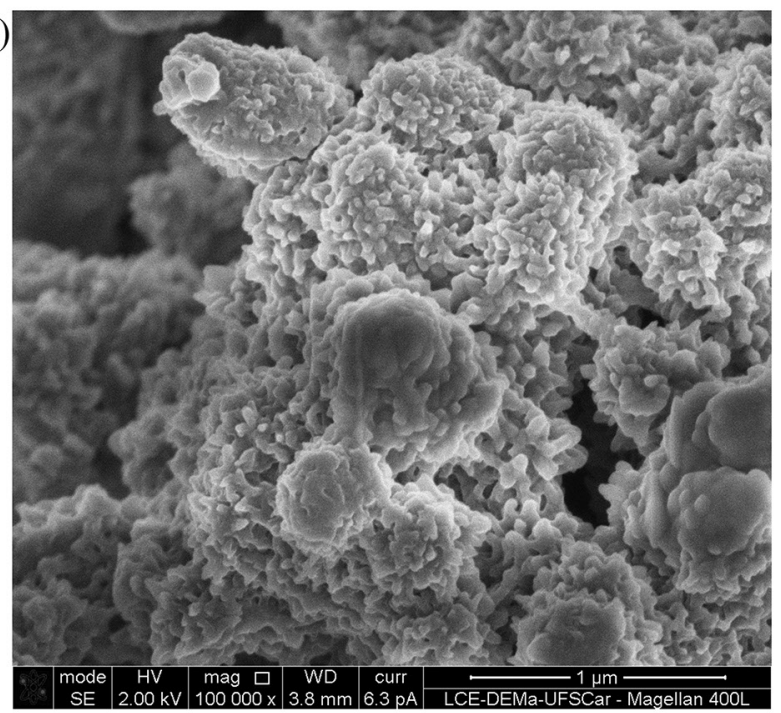

(c)

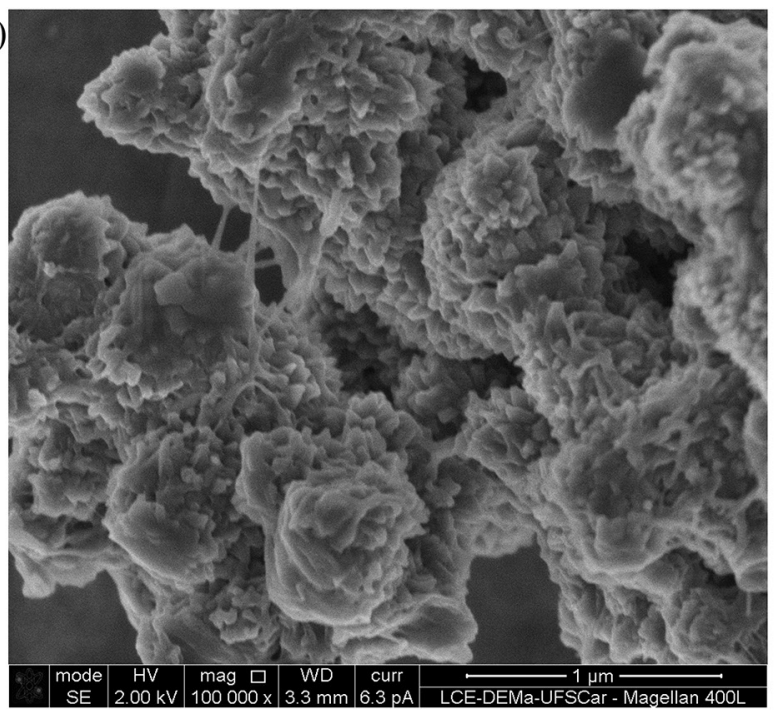

are formed during the induction period just prior to the onset of polymerization and are believed to be aggregates of the anilinium cation and ammonium persulfate anion. Depending on the synthesis experimental conditions (such as ionic strength of the medium, temperature and concentration of the reagents), these aggregates can be spherical or rod-like with the latter leading to a fibrilar morphology of the PAni. Therefore, as all samples were synthesized using the same experimental conditions, only varying the addition of clay or chitosan to the system, the difference in the morphology of the PAni-clay sample when compared to the others can be attributed to the more efficient intercalation of the PAni into the clay interlayer.

(b)

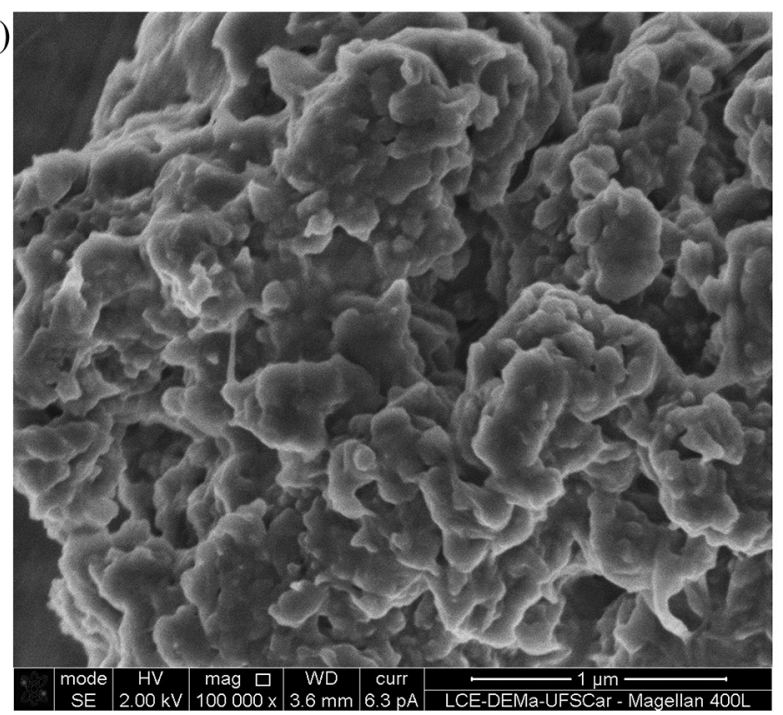

(d)

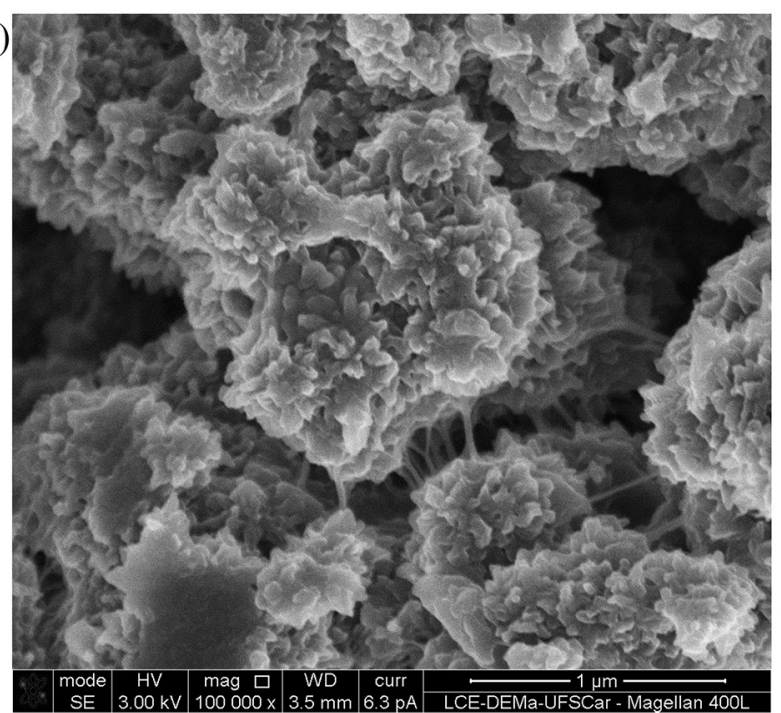

Figure 3. Field emission gun (FEG)-scanning electron microscopy (SEM) images $(\times 100,000)$ of (a) polyaniline (PAni); (b) PAni-clay; (c) PAni-chitosan; and (d) PAni-chitosan-clay. 


\section{Electrical conductivity}

Room temperature DC electrical conductivity values (Table 2) of PAni and its hybrids were measured. All materials have electrical conductivity in the same order of magnitude, even though PAni-chitosan and PAni-chitosanclay present lightly lower values. This behavior can be explained based on the contributions of intra-chain, interchain and inter-particle interactions of each material, since the electrical conductivity depends mainly on the number and mobility of charge carriers that can be correlated with chemical composition and morphology. Furthermore, crystallinity and tacticity play a role in evaluating the electrical properties of polymers. ${ }^{23}$

Table 2. Electrical conductivity $(\sigma)$ of polyaniline (PAni), PAni-clay, PAni-chitosan, and PAni-chitosan-clay

\begin{tabular}{lc}
\hline Sample & $\sigma /\left(\mathrm{S} \mathrm{cm}^{-1}\right)$ \\
\hline PAni & $0.7 \pm 0.2$ \\
PAni-clay & $0.6 \pm 0.2$ \\
PAni-chitosan & $0.3 \pm 0.1$ \\
PAni-chitosan-clay & $0.3 \pm 0.1$ \\
\hline
\end{tabular}

The presence of clay decreases the imperfections of the PAni chain and particle agglomeration, making the PAni-clay composite more planar and conjugated, so the electrons can hop easily. In contrast, the presence of chitosan (a non-conductive polymer) in the PAni-chitosan and PAni-chitosan-clay samples decreases the crystallinity degree and also their electrical conductivity. Despite this, PAni-chitosan-clay presented conductivity values of the same order of magnitude of the other samples showing that the interaction between each compound is able to maintain the conductivity inherent to the PAni.

\section{Spectroelectrochemical characterization}

Figure 4a shows the cyclic voltammograms of PAni, PAni-clay, PAni-chitosan and PAni-chitosan-clay films deposited onto ITO/glass, recorded in $0.1 \mathrm{~mol} \mathrm{~L}^{-1} \mathrm{LiClO}_{4} / 0.1 \mathrm{~mol} \mathrm{~L}^{-1} \mathrm{HClO}_{4}$. The shape of the cyclic voltammograms of the hybrid materials is similar to those PAni, in which were observed two redox pairs. The first redox pair (peaks I and I') was attributed to the leucoemeraldineemeraldine transition, whereas the second (peaks II and II') was assigned to the emeraldine-pernigraniline transition. ${ }^{51}$

A comparison between the results found for the PAni and its hybrids prepared using $\mathrm{HCl}$ as dopant and the cyclic voltammograms of the samples prepared in $\mathrm{PTSA}^{37}$ provides the following observations: $(i)$ in aprotic medium,
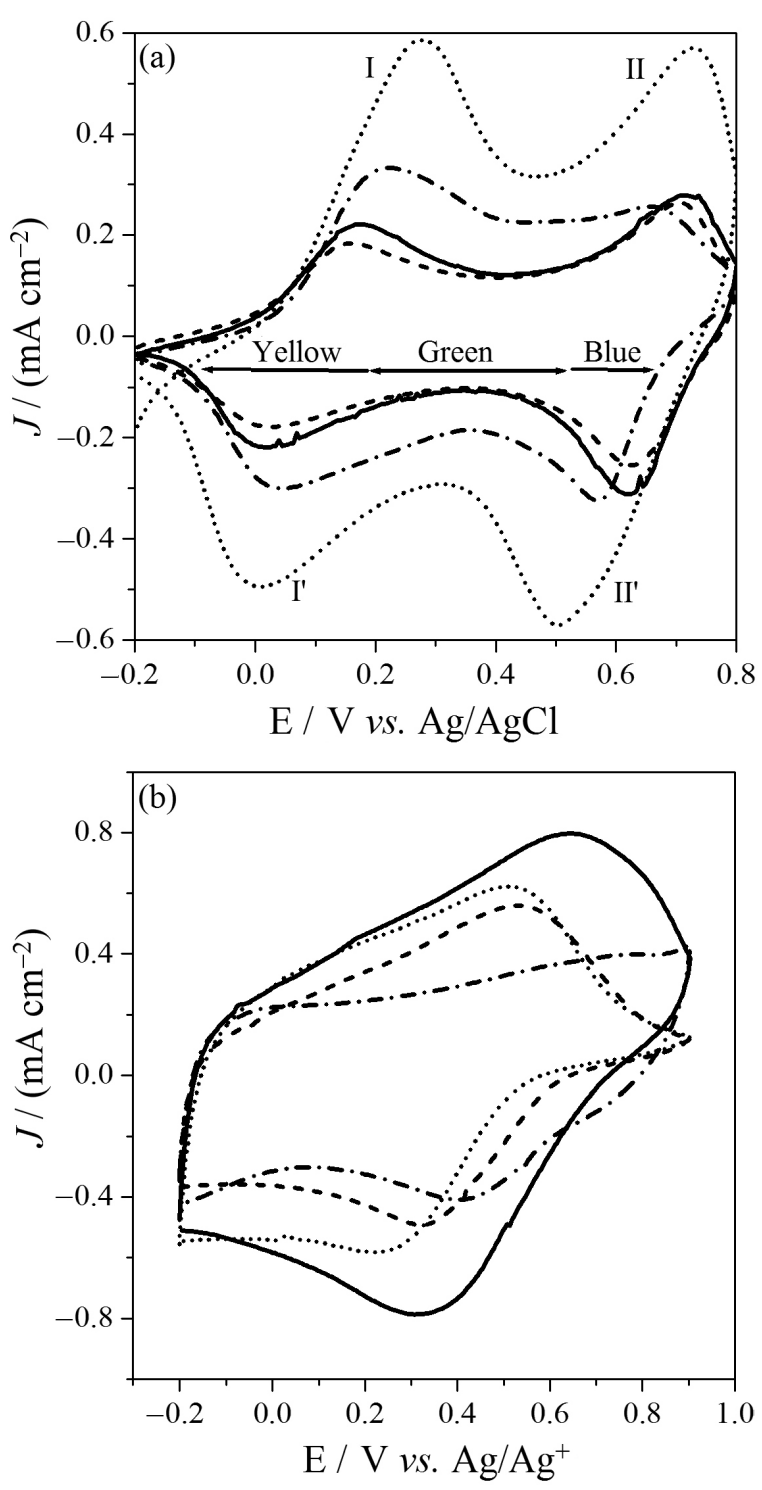

Figure 4. Cyclic voltammograms of $(-)$ polyaniline (PAni); (‥) PAni-clay; (---) PAni-chitosan; and (---) PAni-chitosan-clay films deposited onto indium tin oxide (ITO)/glass: (a) synthesised in $\mathrm{HCl}$ and recorded in $\mathrm{LiClO}_{4} / \mathrm{HClO}_{4}$; and (b) synthesised in $p$-toluenesulfonic acid (PTSA) and recorded in $\mathrm{LiClO}_{4} / \mathrm{CH}_{3} \mathrm{CN}$, with $v=0.02 \mathrm{~V} \mathrm{~s}^{-1}$. I and I' means first redox pair; II and II' means second redox pair. Figure $4 \mathrm{~b}$ was adapted from reference 37 with permission of The Royal Society of Chemistry.

such as acetonitrile, the electrochemical feature of the PAni hybrid films was different from the samples prepared in $\mathrm{HCl}$ and characterized in aqueous acidic conditions, showing capacitive response with just a single defined redox process (Figure 4b); and (ii) when $\mathrm{HCl}$ was used as dopant, the addition of chitosan to the PAni does not alter the electrochemical behavior of the PAni film, while the addition of clay promotes higher current densities and a slight displacement in the $\mathrm{E}_{\mathrm{pa}}$ and $\mathrm{E}_{\mathrm{pc}}$ of both peaks as compared with PAni (Table 3). This behavior can be attributed to the intercalation of the PAni into the clay lamellae that makes the PAni more planar enhancing the 
Table 3. Anodic peak potential $\left(\mathrm{E}_{\mathrm{pa}}\right)$, cathodic peak potential $\left(\mathrm{E}_{\mathrm{pc}}\right)$, and $\lambda_{\max }$ in the reduced $(-0.2 \mathrm{~V})$ and oxidized $(0.8 \mathrm{~V})$ states of polyaniline $(\mathrm{PAni})$, PAni-clay, PAni-chitosan, and PAni-chitosan-clay films

\begin{tabular}{|c|c|c|c|c|c|c|}
\hline \multirow{2}{*}{ Film } & \multirow{2}{*}{$\left.\mathrm{E}_{\mathrm{pa}}{ }^{\mathrm{I}} / \mathrm{V}\right)$} & \multirow{2}{*}{$\mathrm{E}_{\mathrm{pc}}^{\mathrm{r}} / \mathrm{V}$} & \multirow{2}{*}{$\mathrm{E}_{\mathrm{pa}}{ }^{\mathrm{II}} / \mathrm{V}$} & \multirow{2}{*}{$\mathrm{E}_{\mathrm{pc}}^{\mathrm{II}} / \mathrm{V}$} & \multicolumn{2}{|c|}{$\lambda_{\max } / \mathrm{nm}$} \\
\hline & & & & & $-0.2 \mathrm{~V}$ & $0.8 \mathrm{~V}$ \\
\hline PAni & 0.16 & 0.02 & 0.70 & 0.63 & 317 & $624,890^{\mathrm{a}}$ \\
\hline PAni-clay & 0.27 & 0.01 & 0.73 & 0.50 & 323,433 & $850^{\mathrm{a}}$ \\
\hline PAni-chitosan & 0.17 & 0.02 & 0.72 & 0.62 & 319 & $649,930^{\mathrm{a}}$ \\
\hline PAni-chitosan-clay & 0.23 & 0.04 & 0.66 & 0.57 & 318,468 & $900^{\mathrm{a}}$ \\
\hline
\end{tabular}

'Broad band. I and I' means first redox pair; II and II' means second redox pair.

$\pi$-conjugation, which increases the current density when compared to pristine PAni. Furthermore, as the $\mathrm{E}_{\mathrm{pa}}$ and $\mathrm{E}_{\mathrm{pc}}$ values are related to the polymer doping/dedoping process, the intercalation of the PAni into the clay lamellae hinders the access of the counter-ion during the doping process causing the displacement of the peak potentials to more anodic values. On the other hand, the addition of chitosan or clay to the PAni synthesized in PTSA provided a synergistic effect in which the peak potential of PAni-chitosan and PAni-clay films was shifted to less anodic values. These differences suggest that the way of interaction between chitosan or clay and PAni is drastically affected by the dopant and the electrolyte.

The changes in the absorbance spectra of the PAni and its hybrid films as a function of the potential applied to the electrode during cyclic voltammetry are presented in Figure 5. The ultraviolet-visible-near infrared (UV-Vis-NIR) spectra show the characteristic electrochromic behavior of PAni films, in which the color changes from yellowish green in the reduced state $(\mathrm{E}=-0.2 \mathrm{~V}$ vs. $\mathrm{Ag} / \mathrm{AgCl})$ to blue in the oxidized state $(0.8 \mathrm{~V})$. In the reduced state, one can notice a strong absorption peak at $317 \mathrm{~nm}$, attributed to the yellow colored leucoemeraldine form of PAni (benzenoid $\pi$ - $\pi^{*}$ transition). ${ }^{15,52}$ As the applied potential was increasing, a decrease in the intensity of the absorbance at $317 \mathrm{~nm}$ was observed simultaneously to the appearance of a new absorption at $443 \mathrm{~nm}$, corresponding to the polymer in the neutral state $(\mathrm{E}=0.0 \mathrm{~V})$. At more anodic potentials, a new absorbance band in the NIR region $\left(\lambda_{\max }=1066 \mathrm{~nm}\right)$ can be seen concomitantly with the band at $\lambda_{\max }=443 \mathrm{~nm}$, characteristic to the PAni emeraldine form. In the oxidized state $(\mathrm{E}=0.8 \mathrm{~V})$ the PAni spectrum shows the formation of two new bands at $624 \mathrm{~nm}$ and ca. $890 \mathrm{~nm}$ (badly defined peak) that can be assigned to the totally quinoid pernigraniline form of PAni. ${ }^{53}$

The spectra of PAni (Figure 5a) and PAni-chitosan (Figure 5c) have similar features, including the shift of the absorption from the region near $890 \mathrm{~nm}$ towards $620-650 \mathrm{~nm}$ upon increasing potential, indicating the formation of quinoid structures in both materials. Therefore, it is possible suggest that the presence of chitosan in the PAni-chitosan hybrid does not modify the spectroelectrochemical behavior of the PAni. In contrast, at more anodic potentials $(>0.6 \mathrm{~V})$ the absorption of PAni-clay (Figure 5b) and PAni-chitosan-clay (Figure 5d) shifts to shorter wavelength less markedly displaying a broad band in the NIR region, which indicates that the formation of the quinoid fragments in the PAni pernigraniline form is retarded.

In situ colorimetry has been utilized to precisely map the color trajectory associated with the spectral changes of the electrochromic polymers, ${ }^{35-37,52,54}$ giving a numerical description of the color stimulus, and thus providing a more precise way to define color than qualitatively interpreting spectral absorption bands. ${ }^{55}$ Figure 6 shows the CIE 1931 $(\mathrm{x}, \mathrm{y})$ chromaticity coordinates changes as a function of the applied potential for the PAni and PAni hybrid films as calculated from the in situ spectra of Figure 5. In all films the color changes from transparent yellow $(-0.2 \mathrm{~V})$ to green and finally to blue $(0.8 \mathrm{~V})$, wherein this change is much more significant for the PAni-clay film. The color trajectory from $-0.2 \mathrm{~V}$ to $0.8 \mathrm{~V}$ of the PAni and its hybrid films synthesized in $\mathrm{HCl}$ medium looks like a horseshoe, whereas the samples prepared using PTSA as dopant agent, ${ }^{37}$ despite show the same color variation, display a different color trajectory looking like a semi-circle. Furthermore, in that case (PAni and hybrids prepared in PTSA medium) the color changes were more pronounced for the PAni-chitosan-clay film, in contrast to the results obtained for the samples prepared in $\mathrm{HCl}$. These differences in the results obtained for the hybrid materials synthesized in $\mathrm{HCl}$ or in PTSA show the importance of the suitable choice of the acid/dopant agent depending on the final application to be given to the material.

According to the CIELAB ( $\left.\mathrm{L}^{*} \mathrm{a} * \mathrm{~b} *\right)$ chromaticity coordinates (Table 4), with an increase of the applied potential from -0.2 to $0.5 \mathrm{~V}$, a negative change (towards green) in $\mathrm{a}^{*}$ occurs, coupled with a shift to less positive values in $b^{*}$. This means that the color of the films becomes greener and less yellow when the applied potential increases up to $0.5 \mathrm{~V}$ (PAni emeraldine form). At potentials above 

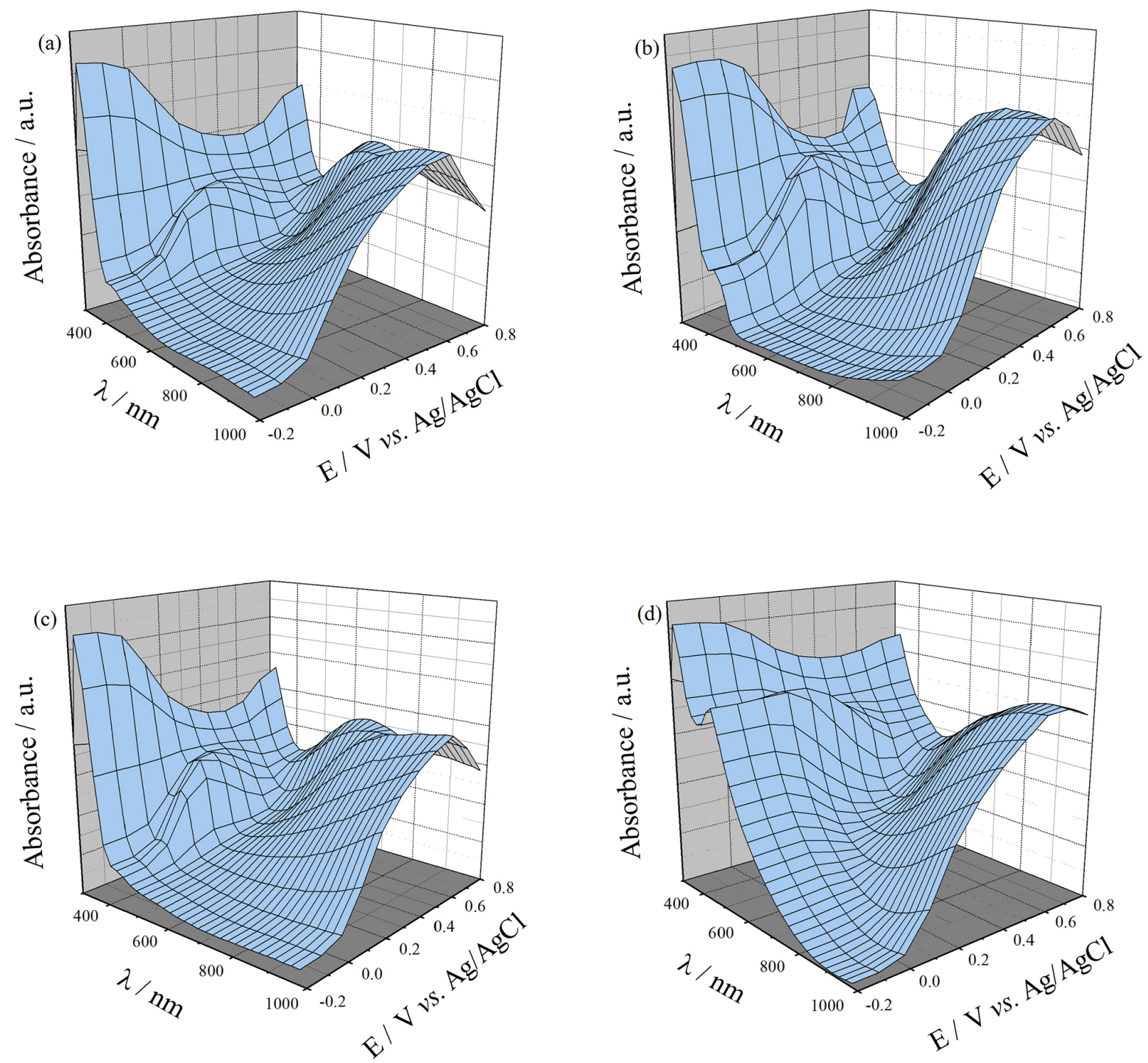

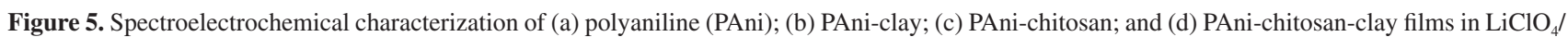
$\mathrm{HClO}_{4} 0.1 \mathrm{~mol} \mathrm{~L}^{-1}$ showing absorbance as a function of the applied potential $(-0.2 \leq \mathrm{E} \leq 0.8 \mathrm{~V} v$ s. $\mathrm{Ag} / \mathrm{AgCl})$.

$0.5 \mathrm{~V}, \mathrm{a} *$ is still negative but its value become less negative while the potential increases and $b^{*}$ is negative (except for PAni-chitosan-clay with $b^{*}=0$ ), quantifying the perceived blue color state of the PAni pernigraniline form as a combination of green and blue at $0.8 \mathrm{~V}$.

\section{Conclusions}

A series of PAni hybrid materials were successfully prepared by the polymerization in situ of aniline with clay and/or chitosan. According to the analysis of the results obtained from FTIR spectroscopy, XRD, SEM, DC electrical conductivity and spectroelectrochemical techniques one can notice that the properties of the films of PAni and its hybrid are strongly influenced by the dopant acid. It was observed the formation of a blend between
PAni and chitosan for PAni-chitosan and PAni-chitosanclay samples synthesized in $\mathrm{HCl}$, instead the formation of a copolymer as proposed for the PAni-chitosan sample prepared using PTSA in our recent work. ${ }^{37}$ Furthermore, the electrochemical and spectroelectrochemical features of these samples synthesized in $\mathrm{HCl}$ were completely different from those ones in PTSA, indicating that the presence of chitosan and clay in the PAni structure affords hybrid materials that present different structure and properties as compared with its individual constituents (PAni, chitosan, and clay) or its constituents combined in pairs (PAni-clay, PAni-chitosan), and also when these materials are prepared in different media. Therefore, the preparation of hybrid materials based on PAni, chitosan and clay leads to new interesting combinations of the properties observed in the corresponding starting materials 
(a)

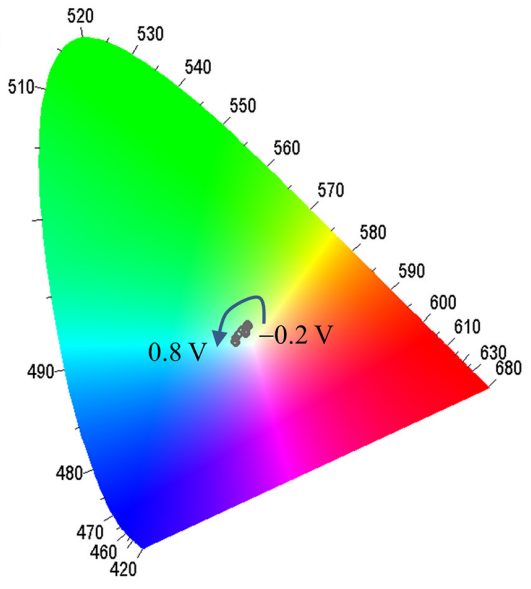

(c)

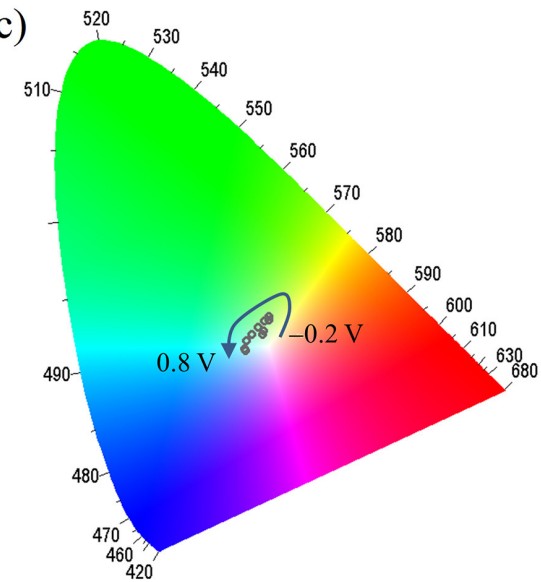

(b)

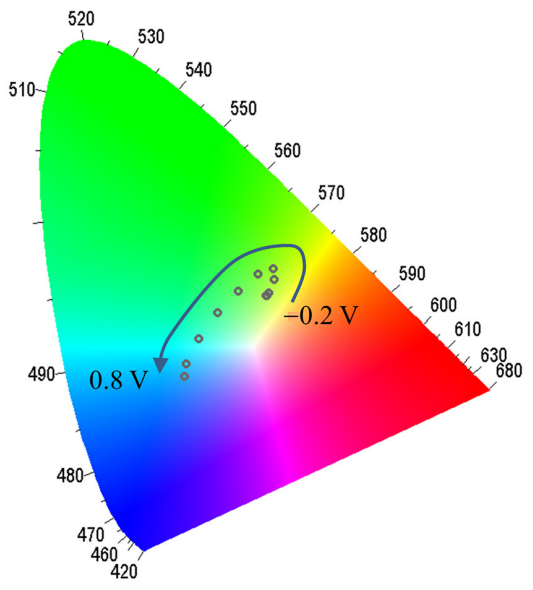

(d)

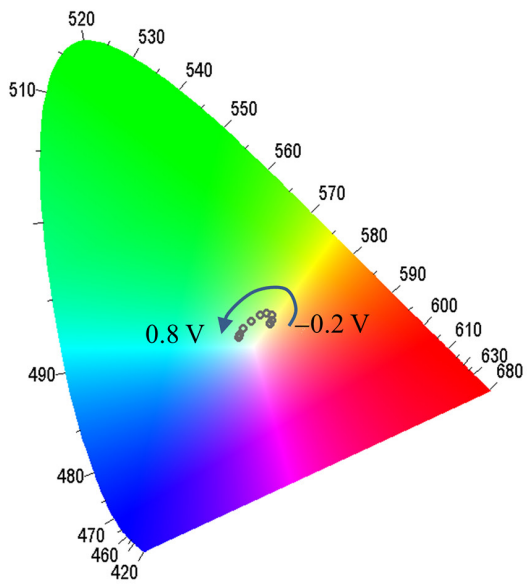

Figure 6. Calculated color trajectory in the Commission Internationale de l'Eclairage (CIE) 1931 color space for (a) polyaniline (PAni); (b) PAni-clay; (c) PAni-chitosan; and (d) PAni-chitosan-clay films deposited onto indium tin oxide (ITO)/glass.

Table 4. Colorimetry properties, according to the CIELAB (L*a*b*) chromaticity coordinates, of polyaniline (PAni), PAni-clay, PAni-chitosan and PAni-chitosan-clay films deposited onto indium tin oxide (ITO)/glass

\begin{tabular}{lcccc}
\hline Film & Potential / V & $\mathrm{L}^{*}$ & $\mathrm{a}^{*}$ & $\mathrm{~b}^{*}$ \\
\hline \multirow{3}{*}{ PAni } & -0.2 & 97 & 0 & 3 \\
& 0.5 & 93 & -4 & 0 \\
& 0.8 & 85 & 0 & -6 \\
\hline \multirow{3}{*}{ PAni-clay } & -0.2 & 78 & -10 & 29 \\
& 0.5 & 56 & -24 & 5 \\
& 0.8 & 31 & -10 & -18 \\
\hline \multirow{3}{*}{ PAni-chitosan } & -0.2 & 95 & 0 & 4 \\
& 0.5 & 87 & -7 & 1 \\
& 0.8 & 75 & -1 & -9 \\
\hline \multirow{3}{*}{ PAni-chitosan-clay } & -0.2 & 68 & 7 & 14 \\
& 0.5 & 72 & -5 & 11 \\
& 0.8 & 66 & -4 & 0 \\
\hline
\end{tabular}

and is an important tool for the fine-tuning of color of PAni composite films with a view to electrochromic applications.
The enhanced electrochromic properties of the PAni hybrid films, particularly the PAni-clay film that shows intense color variation from yellow to green and blue in function of the applied potential, are interesting for the application of these materials as active layers in ECDs, such as displays and smart windows.

\section{Acknowledgments}

The authors wish to thank the granting authorities $\mathrm{CNPq}$, CAPES, FINEP (FUNTEL and CTENERG programs), FAPEAL, FAPESP (2007/50742-2), INCT/INAMI/ CNPq and INCT-INAMI/CAPES/Nanobiotechnology for financial support and for fellowship to R. C. S. (CAPES) and A. S. R. (INCT-INAMI/CNPq, Science without borders). The authors are particularly thankful to Professor Petrus Santa Cruz (Universidade Federal de Pernambuco) for kindly provide the SpectraLux ${ }^{\circledR}$ software, Braskem Co. (Brazil) for a partnership in scientific and technological development. 


\section{References}

1. Teichler, A.; Shu, Z.; Wild, A.; Bader, C.; Nowotny, J.; Kirchner, G.; Harkema, S.; Perelaer, J.; Schubert, U. S.; Eur. Polym. J. 2013, 49, 2186.

2. Logothetidis, S.; J. Mater. Sci. Eng. B 2008, 152, 96.

3. Beajuge, P. M.; Pisula, W.; Tsao, H. N.; Ellinger, S.; Mullen, K.; Reynolds, J. R.; J. Am. Chem. Soc. 2009, 131, 7514.

4. Amb, C. M.; Chen, S.; Graham, K. R.; Subbiah, J.; Small, C. E.; So, F.; Reynolds, J. R.; J. Am. Chem. Soc. 2011, 133, 10062.

5. Gunbas, G.; Toppare, L.; Chem. Commun. (Cambridge, U. K.) 2012, 48, 1083.

6. Camurlu, P.; RSC Adv. 2014, 4, 55832.

7. Silva, A. J. C.; Nogueira, F. A. R.; Tonholo, J.; Ribeiro, A. S.; Sol. Energy Mater. Sol. Cells 2011, 95, 2255.

8. Cai, G. F.; Tu, J. P.; Zhou, D.; Zhang, J. H.; Wang, X. L.; Gu, C. D.; Sol. Energy Mater. Sol. Cells 2014, 122, 51.

9. Wei, J.; Xiong, S.; Bai, Y.; Jia, P.; Ma, J.; Lu, X.; Sol. Energy Mater. Sol. Cells 2012, 99, 141.

10. Wei, H.; Zhu, J.; Wu, S.; Wei, S.; Guo, Z.; Polymer 2013, 54, 1820 .

11. Mao, L.; Zhang, K.; Chan, H. S. O.; Wu, J.; J. Mater. Chem. 2012, 22, 80 .

12. Abaci, U.; Guney, H. Y.; Kadirogu, U.; Electrochim. Acta 2013, 96, 214.

13. Kalagi, S. S.; Mali, S. S.; Dalav, D. S.; Inamdar, A. I.; Im, H.; Patil, P. S.; Synth. Met. 2011, 161, 1105.

14. Cao, Y.; Smith, P.; Heeger, A. J.; Synth. Met. 1989, 32, 263.

15. Nekrasov, A. A.; Gribkova, O. L.; Eremina, T. V.; Isakova, A. A.; Ivanov, V. F.; Tverskoj, V. A.; Vannikov, A. V.; Electrochim. Acta 2008, 53, 3789.

16. Morita, M.; J. Polym. Sci., B: Polym. Phys. 1994, 32, 231.

17. Luong, N. D.; Korhonen, J. T.; Soininen, A. J.; Ruokolainen, J.; Johansson, L.-S.; Seppälä, J.; Eur. Polym. J. 2013, 49, 335.

18. Pud, A.; Ogurtsov, N.; Korzhenko, A.; Shapoval, G.; Progr. Polym. Sci. 2003, 28, 1701.

19. Barthet, C.; Armes, S. P.; Chehimi, M. M.; Bilem, C.; Omastova, M.; Langmuir 1998, 14, 5032.

20. Fatyeyeva, K.; Pud, A. A.; Bardeau, J. F.; Tabellout, M.; Mater. Chem. Phys. 2011, 130, 760.

21. Guo, B.; Finne-Wistrand, A.; Albertsson, A.-C.; Biomacromolecules 2011, 12, 2601.

22. Lukasiewicz, M.; Ptaszek, P.; Ptaszek, A.; Bednarz, S.; Staerke 2014, 66, 582.

23. Yavuz, A. G.; Uygun, A.; Can, H. K.; Carbohydr. Res. 2011, 346, 2063.

24. Zhang, J.; Tu, J. P.; Zhang, D.; Qiao, Y. Q.; Xia, X. H.; Wang, X. L.; Gu, C. D.; J. Mater. Chem. 2011, 21, 17316.

25. Khairy, M.; Gouda, M. E.; J. Adv. Res. 2015, 6, 555.

26. Bae, W. J.; Davis, A. R.; Jung, J.; Jo, W. H.; Carter, K. R.;
Coughlin, E. B.; Chem. Commun. (Cambridge, U. K.) 2011, 47, 10710.

27. Mostafaei, A.; Zolriasatein, A.; Progr. Nat. Sci. 2012, 22, 273.

28. Baldissera, A. F.; Souza, J. F.; Ferreira, C. A.; Synth. Met. 2013, 183, 69.

29. Pedroso, C. C. S.; Junqueira, V.; Rubinger, C. P. L.; Martins, T. S.; Faez, R.; Synth. Met. 2013, 170, 11.

30. Rosa, A. C. A.; Correa, C. M.; Faez, R.; Bizeto, M. A.; Camilo, F. F.; RSC Adv. 2013, 3, 26142.

31. Ribeiro, A. S.; Machado, D. A.; Santos Filho, P. F.; de Paoli, M.-A.; J. Electroanal. Chem. 2004, 567, 243.

32. Ribeiro, A. S.; Silva, A. U.; Navarro, M.; Tonholo, J.; Electrochim. Acta 2006, 51, 4892.

33. Silva, A. J. C.; Ferreira, S. M. F.; Santos, D. P.; Navarro, M.; Tonholo, J.; Ribeiro, A. S.; Sol. Energy Mater. Sol. Cells 2012, $103,108$.

34. Almeida, A. K. A.; Dias, J. M. M.; Silva, A. J. C.; Navarro, M.; Alves Junior, S.; Tonholo, J.; Ribeiro, A. S.; Synth. Met. 2013, $171,45$.

35. Silva, A. J. C.; Nogueira, V. C.; Santos, T. E. A.; Buck, C. J. T.; Worrall, D. R.; Tonholo, J.; Mortimer, R. J.; Ribeiro, A. S.; Sol. Energy Mater. Sol. Cells 2015, 134, 122.

36. Ribeiro, A. S.; Mortimer, R. J. In Electrochemistry: Volume 13 (Specialist Periodical Reports); Banks, C.; Mortmer, R.; McIntosh, S., eds.; Royal Society of Chemistry: London, 2016, ch. 2 .

37. Silva, R. C.; Sarmento, M. V.; Nogueira, F. A. R.; Tonholo, J.; Mortimer, R. J.; Faez, R.; Ribeiro, A. S.; RSC Adv. 2014, 4, 14948.

38. Mortimer, R. J.; Varley, T. S.; Displays 2011, 32, 35.

39. Mortimer, R. J.; Varley, T. S.; Sol. Energy Mater. Sol. Cells 2012, 99, 213.

40. Ismail, Y. A.; Shin, S. R.; Shin, K. M.; Yoon, S. G.; Shon, K.; Kim, S. I.; Kim, S. J.; Sens. Actuators, B 2008, 129, 834.

41. Yavuz, A. G.; Uygun, A.; Bhethanabotla, V. R.; Carbohydr. Polym. 2010, 81, 712.

42. Trchová, M.; Stejskal, J.; Pure Appl. Chem. 2011, 83, 1803.

43. Janaki, V.; Oh, B.-T.; Shanthi, K.; Lee, K.-J.; Ramasamy, A. K.; Kamala-Kannan, S.; Synth. Met. 2012, 162, 974.

44. Ray, S. S.; Bousmina, M.; Prog. Mater. Sci. 2005, 50, 962.

45. Varghese, J. G.; Kittur, A. A.; Rachipudi, P. S.; Kariduraganavar, M. Y.; J. Membr. Sci. 2010, 364, 111.

46. Zhu, H. Y.; Jiang, R.; Xiao, L.; App. Clay Sci. 2010, 48, 522.

47. Wan, Y.; Wu, H.; Yu, A. X.; Wen, D. J.; Biomacromolecules 2006, 7, 1362.

48. Pouget, J. P.; Jozefowicz, M. E.; Epstein, A. J.; Tang, X.; MacDiarmid, A. G.; Macromolecules (Washinghton, DC, U.S.) 1991, 24, 779.

49. Sudha, J. D.; Sasikala, T. S.; Polymer 2007, 48, 338.

50. Zhang, X.; Kolla, H. S.; Wang, X.; Raja, K.; Manohar, S. K.; Adv. Funct. Mater. 2006, 16, 1145. 
51. Pruneanu, S.; Veress, E.; Marian, I.; Oniciu, L.; J. Mater Sci 1999, 34, 2733.

52. Huang, L.-M.; Chen, C.-H.; Wen, T.-C.; Gopalan, A.; Electrochim. Acta 2006, 51, 2756.

53. Tóth, P. S.; Samu, G. F.; Endrödi, B.; Visy, C.; Electrochim. Acta 2013, 110, 446.

54. Rauh, R. D.; Wang, F.; Reynolds, J. R.; Meeker, D. L.; Electrochim. Acta 2001, 46, 2023.
55. Wyszecki, G.; Stiles, W. S.; Color Science: Concepts and Methods, Quantitative Data and Formulae, $2^{\text {nd }}$ ed.; John Wiley and Sons: New Jersey, 1982.

Submitted: January 27, 2016

Published online: March 3, 2016

FAPESP has sponsored the publication of this article. 